\title{
Aproximación a la geografía literaria de las tradiciones palmistas
}

\author{
José Vásquez Peña \\ Instituto Ricardo Palma \\ Jocavape16@hotmail.com \\ (...) Cuentan que Ulises harto de prodigios \\ lloró de amor al divisar su Ítaca \\ Verde y humilde. El arte es esa Ítaca \\ De verde eternidad no de prodigios (...). ${ }^{1}$
}

Jorge Luis Borges

\section{Resumen}

La investigación se orienta a demostrar cómo la prodigiosa geografía iqueña influyó en la producción palmista. Ello se aprecia en la mención de nombres de lugares y de la idiosincrasia de los iqueños, en diferentes etapas de su evolución: desde 1412 (data de la tradición: La Achirana del Inca, la más antigua, si nos atenemos a la época histórica que narra, hasta 1838, fecha de la última tradición seleccionada para el análisis: un cuociente inverosímil.) Este alineamiento histórico posibilita una cabal comprensión de la obra de Palma en las once tradiciones dedicadas a Ica.

En sí, a través del estudio expresamos un contrapunto entre los factores temporal, espacial y aspectual, que se observan en las señaladas tradiciones que dan una visión especial de la Ica real. Mostrando, en el plano textual, las bondades de su geografía y la naturaleza de su gente.

Palabras clave: Geografía literaria, perceptiva literaria, connotación legendaria, claves geográficas individuales, claves geográficas colectivas, iqueñidad, idiosincrasia.

\section{Abstract}

The work is oriented to demonstrate how the prodigious Iqueña geography influenced the production palmista. This can be seen in the profuse mention of place names and

1 BORGES, Jorge Luis. Arte Poética. En "El Hacedor." Obras completas. EMECE editores. 1974. Buenos Aires 
the idiosyncrasy of the Iqueños, in the different stages of evolution, since 1412 (date of the tradition: The Achirana of the Inca, the oldest if we stick to the historical epoch Tells us, until 1838, the date of the last tradition selected for analysis: An unlikely quotient.) This historical alignment enables a full understanding of Pälma's works in the eleven traditions dedicated to Ica.

In itself through the study we express a counterpoint of the factors: Temporal, spatial and aspectual that are observed in the mentioned traditions, that give a unique vision of the Ica real, showing in the textual plane the kindness of its geography and the nature of its people.

\section{Keywords}

Literary geography, literary perceptive, legendary connotation, individual geographic keys, collective geographic keys, idiosyncrasy.

\section{José Vásquez Peña}

Profesor universitario. Ha publicado investigaciones sobre la obra poética de Abraham Valdelomar y la narrativa iqueña en el libro Las huellas del Hipocampo de Oro. Asimismo, es editor de importantes títulos como El Parral de las Ánimas, Antología de la Poesía Infantil Peruana del Siglo XX, entre otros. 
El epígrafe es elucidatorio. Con nitidez explica la vinculación indestructible que existe entre las obras literarias y el entorno geográfico que las generó. En su poética, de cuyo contexto hemos extraído la estrofa que preside esta ponencia, Jorge Luis Borges asume la posición de los escritores que rinden pleitesía al espacio geográfico que les inspira para poder crear.

Bajo la preceptiva literaria actual la importancia de la geografía en el texto se explica a través de la relación interdisciplinaria que se ha convertido en una matriz interpretativa eficaz para entender un problema; en este caso, el comportamiento de la geografía (como ciencia y como espacio) en la construcción de textos literarios. Vistos así, estos están sujetos a circunstancias: espaciales, temporales, culturales, que son abordados con el poder de la lengua y del lenguaje, con la acción de la literatura.

A este enfoque que prioriza el impacto del lugar en el efecto estético, que siempre ha existido y se le llama ahora geografía literaria, alude el siguiente postulado: los nombres de los lugares, las creencias, las supersticiones, en suma, la idiosincrasia de sus habitantes, orientan ¿o, tal vez? definen la creación literaria.

Este preámbulo lo culminamos con una aseveración del semiólogo francés Roland Barthes: Todas las ciencias están presentes en el monumento literario, y la geografía no podía ser diferente.

Las tradiciones peruanas, monumento literario bajo esta dirección interpretativa encierran una gran riqueza de nombres de lugares, de circunstancias, de todo el Perú y de todos los tiempos; ofrece un tesoro en la descripción y narración no solo de lugares y costumbres de la costa, sierra y selva, sino que abarca la subjetividad de personajes que no representan sino al hombre peruano de este y de otros tiempos pretéritos. Tiempos y hechos que han servido de simiente de la peruanidad, de aquel sentimiento de abnegado amor a la patria. 
El terreno de la investigación propuesta es tan vasto que en esta ponencia solo pretendo aproximarme a parte de la geografía de las tradiciones palmistas, la referida a Ica, a la realidad que más conocemos y que la analizamos en base a las once tradiciones que escribiera Palma sobre la tierra del huarango, el sol, las encantadas dunas y el chaucato. Inobjetablemente, la lectura de ellas construye, en el plano regional, un sentimiento de iqueñidad.

Vale decir: Las Tradiciones Peruanas, que son relatos generalmente legendarios, contienen también elementos geográficos, históricos, etimológicos, antropológicos, psicológicos y otros.

De ese crisol de información provendrá nuestra interpretación.

La primera tradición de nuestro análisis, dada su connotación legendaria, es una ambientada geográficamente en un misterioso caserío iqueño, ubicado al sur oeste de Ica: Cachiche, desértico lugar, rodeado de dunas, huarangos y palmeras. El motivo literario de las Brujas de Cachiche, (Cabel, 2007: 18) gira en torno a un elemento mítico-simbólico.

El primer brujo, practicante de este menester, es tratado como un ser mítico debido a que en él se integran sus seguidores en el tiempo, llegando hasta las brujas actuales que habitan en esa tierra recóndita practicando la hechicería, ejerciendo la medicina natural. En esa geografía fabulosa, que para lograr el resultado estético solo necesita ser trasladada al texto, se describe el paisaje maravilloso de enormes dunas encantadas (de las cuales nacen los diversos paisajes artísticos: literarios y pictóricos, eternos en las obras de iqueños y foráneos que de manera recurrente loan a las dunas, su paisaje natural, prodigiosa geografía). 
Dunas, ornadas con viejos huarangos que han vencido al tiempo, compitiendo en hechizo con la palmera de siete cabezas sobre la cual pende la predicción siguiente: cuando la séptima cabeza que se encuentra seca reverdezca, se producirá el fin del mundo.

Esta geografía que ahora la compararíamos con la Comala de Rulfo o el Macondo Garciamarquiano, inspiró en su época a Ricardo Palma para escribir esta icónica tradición sobre Ica. En ella encontramos, también, la importancia que daba Palma a las brujas de Cachiche: "Como las brujas de Mahudes y Zugarramundi, en España, son famosas en Ica las de Cachiche, condado o señorío de un amigo. Cachichana y bruja son sinónimos". (Ibíd., p. 21).

No solo hay en la tradición aludida un tratamiento del tema desde el punto .de vista geográfico, sino que Palma apunta igualmente a la idiosincrasia del pueblo:

pueblo iqueño (que) es dado a creer en lo sobrenatural, y ni con tiranas carretas se le hace entender que es mentira aquello que las brujas viajan por los aires, montadas en cañas de escoba, y que hacen maleficios, y que leen sin deletrear en el libro del porvenir, como yo en un mamotreto de este siglo. (Ibíd., p. 18).

En La Achirana del Inca, hay referencia a otro lugar de Ica, Palma nos dice:

El Inca Pachacutec, acompañado de su hijo el principal Yupanqui y de su hermano Capac-Yupanqui, emprendió la conquista del valle de Ica. (...) Visitando Pachacutec el feraz territorio que acababa de sujetar a sus dominios, detúvose una semana en el pago llamado Tate. (Ibíd., p. 13). 
En la misma tradición se menciona una secuencia de lugares de la campiña iqueña ordenados de norte a sur, siguiendo el cauce abierto por los hombres del Inca:

El agua de la Achirana del inca suministra abundante riego a las haciendas que hoy se conocen con los nombres de Cabalina, Belén, San Jerónimo, Tacama, San Martín, Mercedes, Santa Bárbara, Chanchajaya, Santa Elena, Vista Alegre, Sáenz, Parcona, Tayamana, Pongo, Pueblo Nuevo, Sunampe y, por fin Tate. (Ibíd., p. 14).

Entiéndase que partiendo del texto comentado, Cachiche, Tallamana, etc., aparecen primero como conceptos geográficos, adquieren luego un carácter metafórico y provisional, hasta alcanzar progresivamente un carácter conceptual y definitivo.

Estos lugares que son aisladamente claves geográficas individuales, luego del análisis de las once tradiciones adquieren la significación de claves geográficas de conjunto que viabilizan la percepción de una Ica integrada en el espacio y en el tiempo.

En Orgullo de Cacique, hallamos más referentes geográficos: el naufragio del Vapor Rímac, el 5 de Marzo de 1855, en los arrecifes de la punta de San Juan. (Ibíd., p. 16). Las primeras líneas de esta tradición indican a San Juan de Marcona (distrito de NascaIca) como el lugar de este hecho. Apreciamos asimismo otros lugares como Nasca, Chaviña, Chocavento, Acarí, Atiquipa, algunos de los cuales pertenecen a la Región Arequipa.

En Cortar por lo sano hay una mención a la antigua Ica, "Era administrador de una hacienda de viñas, a tres leguas de la por entonces villa de Valverde y hoy ciudad de ciudad", (Ibíd., p. 25). y a lugares urbanos de aquella Ica, al referirse a los estragos ocasionados por el terremoto del 12 de Mayo de 1664: "Las Iglesias de San Francisco y San Agustín, fabricadas con mucha 
solidez, se desplomaron, y únicamente la capilla del Señor de Luren resistió a la furia del terremoto". (Ibíd., p. 27). De las iglesias mencionadas, actualmente solo sigue en pie la de San Francisco, no la que menciona Palma en esa tradición sino la nueva cuya erección se produjo en la década del 50 de la centuria pasada, la misma que resistió el terremoto del 2007. La de San Agustín que menciona Palma, existió en la Plaza de Armas: "Desgraciadamente, este templo que ha pasado a la historia fue derribado por el terremoto que hubo el 30 de Mayo de 1813" (Rossel, 1954: 88). La capilla del Señor de Luren que aparece en la tradición es la que existía hasta antes del incendio de 1918. Luego se construyó la Iglesia que alcanzó renombre nacional y, lamentablemente, fue destruida por el terremoto del 2007.

En la tradición El que más vale no vale tanto como Valle vale, dedicada a narrar hechos y situaciones de Don Alonso Gonzales del Valle, Marqués de Campoameno, figuran nombres de lugares como Pisco, Castrovirreyna, Chincha.

En iMata!, iMata! iMata!, tradición que tiene como personaje protagónico también a Don Alonso Gonzales del Valle, menciónase como lugar de los acontecimientos a Ica De Asta y rejón, es una tradición en la cual sus personajes, sobre todo Doña Feliciana Chávez, realizan sus correrías en el ámbito de Lima e Ica.

En la tradición: Un cuociente inverosímil hallamos nombres de lugares como Haciendo de Cipiona, Palpa, Pisco, Poruma.

La tradición más sustanciosa en cuanto a referencias imaginarias es Dónde y cómo el diablo perdió el poncho. Si bien es cierto Ica figura como lugar geográfico, esta se encuentra insertada en un mundo lleno de magia en donde se tejen situaciones inverosímiles: la llegada de Jesucristo y posteriormente del diablo a esta Ica textual: 
Pues, señor cuando nuestro Señor Jesucristo peregrinaba por el mundo, caballero en mansísima borrica, dando vista a los ciegos y devolviendo a los tullidos el uso y abuso de sus miembros, llegó a una región donde la arena formaba horizonte. De trecho en trecho alzábase enhiesta y gárrula una palmera, bajo cuya sombra solían detenerse el Divino Maestro y sus discípulos escogidos, los que, como quien no quiere la cosa, llenaban de dátiles las alforjas.

Aquel arenal parecía ser eterno, algo así como Dios sin principio ni fin. (Cabel, 2008: 41)

El mundo imaginario trazado por Palma en esta tradición está sustentado en la geografía desértica de Ica. Apréciase en ella que si no hay una creación total de un lugar, existe una modificación sustantiva de la geografía iqueña para adecuarla al propósito estético de tornarla un lugar misterioso que dé marco a la presencia de personajes como Jesucristo o como al diablo que imaginariamente visitaron la tierra iqueña. Es decir se ha logrado crear un mundo de magia en donde la realidad geográfica se ha reelaborado literariamente.

Lo expresado se confirma con el siguiente párrafo que trascribimos:

El señor se puso la mano sobre los ojos. Formando visera para mejor concentrar la visual, y dijo:

- Allí hay población, Pedro, tú que entiendes de náutica y geografía, ¿me sabrás decir qué ciudad es esa?

San Pedro se relamió el piropo y contestó:

- Maestro, esa ciudad es Ica

- iPues Pica, hombre, pica! (Ibíd., p. 41). 
Al finalizar, enfatizamos: debemos articular todas las claves encontradas en las diferentes tradiciones para comprender en qué medida se ha producido en los textos palmistas la relación de la creación literaria con el entorno, es decir, con el espacio geográfico que sirvió de marco para el logro del efecto estético.

\section{Bibliografía}

Borges, J.L. (1974). Arte Poética. El Hacedor. Obras completas. Buenos Aires: Emence editores.

Cabel, J. (2008). Ica en las Tradiciones de Ricardo Palma. Editorial San Marcos. Lima

Huarag Álvarez, E. (2015). Palma, el arte de narrar y el rescate de la oralidad popular. Aula Palma No 15. Instituto Ricardo Palma. Lima. p. 43.

Tauzin Castellanos. I. (1999). Las Tradiciones de Ricardo Palma: Claves de una coherencia. Lima Universidad Ricardo Palma/Centro de Investigaciones.

Rossel Castro, A. (1954). Caciques y Templos de Ica. Lima: Talleres de la Penitenciaria de Lima, pp. 88.

Recibido: 15 al 30 de octubre 2016

Aprobado: 1 al 15 de diciembre 2016 